\title{
ANALISIS MINAT BELAJAR MATEMATIKA SISWA SMP KELAS VIII PADA MATERI PERSAMAAN GARIS LURUS BERBANTU APLIKASI GEOGEBRA
}

\author{
Arpin Chronika Saida Manalu' ${ }^{1}$, Yeti Jumiati ${ }^{2}$, Wahyu Setiawan ${ }^{3}$ \\ 1,2,3 IKIP Siliwangi, Jl. Terusan Jendral Sudirman, Cimahi Tengah, Kota Cimahi, Jawa Barat \\ Arpinchronika240@gmail.com
}

\begin{abstract}
This research was conducted to analyze the interest in learning of junior high school students when conducting learning aided by the application of geogebra in the material of straight line equatios. The method used in this study is a quasi experiment with percentage quantitative descriptive techniques. The population of this study is students at junior high school Pasundan 9 Bandung, by taking a sample is 33 students of class VIII-C at junior high school Pasundan 9 Bandung. The instrument used in this study was a non-test instrument in the form of a questionnaire about students interest in learning after learning to use a geogebra application consisting of 20 statements. The result of this study are learning straight line equations in whose learning is assisted by the geogebra application get a positive response and can increase student interest in learning. Which can be seen from the average percentage obtained for each indicator $70,74 \%$ which means that most students already have an interest in learning mathematics learning mathematics learning assisted by geogebra applications.
\end{abstract}

Keywords: Geogebra, interest in learning, straight line equation.

\begin{abstract}
Abstrak
Penelitian ini dilakukan untuk menganalisis minat belajar pada siswa SMP saat melakukan pembelajaran berbantukan aplikasi geogebra pada materi persamaan garis lurus. Metode yang digunakan dalam penelitian ini adalah eksperimen kuasi dengan teknik deskriptif kuantitatif persentase. Populasi dari penelitian ini adalah siswa di SMP Pasundan 9 Bandung, dengan mengambil samplenya yaitu 33 siswa kelas VIII-C di SMP Pasundan 9 Bandung. Instrumen yang digunakan dalam penelitian ini berupa instrumen non-test berupa angket tentang minat belajar siswa setelah belajar menggunakan aplikasi geogebra yang terdiri dari 20 pernyataan. Hasil yang didapat dari penelitian ini adalah pembelajaran persamaan garis lurus yang pembelajarannya berbantu aplikasi geogebra mendapat respon positif dan dapat meningkatkan minat belajar siswa. Yang dapat dilihat dari persentase ratarata tiap indikator yaitu $70,74 \%$ yang berarti bahwa sebagian besar siswa telah memilki minat belajar dalam pembelajaran matematika berbantukan aplikasi geogebra.
\end{abstract}

Kata kunci: Geogebra, Minat belajar, Persamaan garis lurus.

Belajar ialah suatu proses agar dapat mengetahui, mengerti dan melaksanakan suatu hal dari yang belum diketahui, belum dimengerti dan tidak bisa dilaksanakan yang sengaja dilakukan oleh individu (Widyaningrum \& Murwanintyas, 2013). Sehingga dengan belajar harapannya seseorang dapat meningkatkan kemampuan afektif, kognitif, juga psikomotoriknya. Belajar sudah dilakukan seseorang sejak bayi sampai usia lanjut sekalipun.. Matematika ialah salah satu ilmu dan juga pelajaran yang penting guna dalam perkembangan ilmu pengetahuan dan juga perkembangan teknologi (Pratiwi, Kuswardi, \& Fitriana, 2018). Matematika penting diberikan kepada setiap individu, mengingat matematika banyak dimanfaatkan hampir disetiap bidang kehidupan sehari-hari setiap mahluk hidup. Hal ini sesuai dengan yang dipaparkan oleh Sholihah \& Mahmudi (2015), bahwa pelajaran matematika penting diberikan disemua jenjang pendidikan mulai dari sekolah dasar sampai ke jenjang yang lebih tinggi sebagai ilmu dasar untuk penerapan di bidang ilmu lain. Matematika ilmu yang identik dengan perhitungan dan rumus. Dengan belajar matematika dapat melatih kemampuan yang terdapat dalam diri siswa untuk dapat mengaitkan suatu konsep ke konsep lain juga mampu untuk memecahkan 
permasalahan matematika secara analitis, logis dan sistematis (Putra et al., 2018). Keberhasilan belajar matematika yang dilakukan oleh siswa dapat terlihat dari hasil belajar yang diperoleh siswa. Keberhasilan yang diperoleh siswa dari belajar dapat dipengaruhi dari bermacam-macam faktor diantaranya adalah minat belajar yang ada pada siswa.

Minat belajar siswa adalah suatu perasaan tertarik dan suka terhadap suatu hal yang sedang dipelajari yang muncul dari diri sendiri (Flora Siagian, 2015). Minat belajar pada seorang individu dapat ditumbuhkan oleh dirinya sendiri atau bisa juga dipengaruhi oleh orang atau sesuatu diluar dirinya misalnya, guru tua, teman, buku, media cetak, media elektonik juga hal lainnya (Hendriana, Rohaeti, \& Sumarmo, 2017). Pembelajaran yang menyenangkan serta tidak monoton juga memberikan kebebasan kepada semua siswa untuk menyampaikan ide-ide yang dimiliki dapat menambah minat belajar pada siswa itu sendiri (Lestari, 2015). Banyak cara yang dapat dilakukan dan diterapkan pada proses pembelajaran agar menjadi menarik dan tidak monoton yaitu dengan menggunakan media dalam pembelajarannya.

Media pembelajaran ialah alat bantu yang sengaja dibuat dan digunakan untuk memudakhan siswa mempelajari materi yang dipaparkan selama proses kegiatan belajar mengajar. Ada banyak macam media pembelajaran yang dapat digunakan, salah satunya yaitu yang berbasis teknologi yaitu aplikasi Geogebra (Nur, 2016). Geogebra dibuat untuk mempermudah siswa dalam mempelajari geometri sekaligus dengan aljabar secara bersamaan (Farihah, 2015). Geogebra adalah program dinamis yang memiliki beragam fasilitas yang dapat dipakai sebagai media yang memudahkan kegiatan pembelajaran matematika untuk menvisualisasikan konsep-konsep dalam matematika juga dapat dipakai sebagai alat bantu untuk membangun konsep-konsep dalam matematika (Sihwidi, 2016). Salah satu contoh materi dari matematika yang cocok menggunakan alat bantu aplikasi Geogebra ialah Persamaan Garis lurus. Melalui aplikasi geogebra, siswa dapat mempelajari konsep materi dengan mudah khususnya menentukan nilai gradien, karena dengan aplikasi geogebra siswa bisa melihat bentuk grafik dengan jelas sehingga mempermudah siswa untuk memahami mana itu komponen $\mathrm{X}$, komponen $\mathrm{Y}$, dan nilai dari arah grafik tersebut. Aplikasi ini juga membuat guru dapat melakukan manipulasi dengan mudah pada grafik dengan mengubah nilai koefisien dan konstanta pada persamaan grafik sehingga pembelajaran menjadi lebih efektif.

Dengan adanya pemanfaatan media pembelajaran aplikasi geogebra ini tentu akan membuat proses pembelajaran menjadi lebih menarik bagi siswa dan tentunya proses belajar tidak akan monoton. Jika pembelajaran sudah menarik tentu siswa akan tertarik mengikuti kegiatan pembelajaran dengan baik sampai selesai, sehingga bisa meningkatkan minat belajar matematika pada siswa.

Dari latar belakang diatas, peneliti tertarik untuk melakukan penelitian dengan berjudul "Analisis Minat Belajar Matematika Siswa SMP Kelas VIII pada materi Persamaan Garis Lurus berbantu Aplikasi Geogebra". 
Analisis Minat Belajar Matematika Siswa SMP Kelas VIII Pada Materi Persamaan Garis Lurus Berbantu Aplikasi

\section{METODE}

Metode yang digunakan dalam penelitian ini ialah eksperimen kuasi dengan teknik deskriptif kuantitatif persentase, yaitu teknik penelitian yang menghasilkan data deskriptif dari persentase jawaban siswa yang memuat 5 indikator skala minat belajar siswa melalui angket yang diberikan kepada siswa. Melalui penggunaan metode deskriptif dalam penelitian ini diharapkan bisa mendeskripsikan bagaimana pengaruh pembelajaran dengan berbantu aplikasi Geogebra terhadap peningkatan minat belajar siswa pada materi persamaan garis lurus. Populasi dalam penelitian ini ialah siswa di SMP Pasundan 9 Bandung, dan samplenya yaitu 33 siswa kelas VIII-C di SMP Pasundan 9 Bandung. Instrumen yang digunakan berupa instrumen non-test berupa angket tentang minat belajar siswa setelah belajar menggunakan aplikasi geogebra, yang terdiri dari 20 pernyataan dengan masing-masing 10 pernyataan positif juga 10 pernyataan negatif dengan 4 pilihan jawaban yaitu SS (Sangat Setuju), S (Setuju), TS (Tidak Setuju), STS (Sangat Tidak Setuju).

\section{Tabel 1.}

Butir Skala Sikap Minat Belajar Siswa

\begin{tabular}{|c|c|c|c|c|c|}
\hline \multirow{2}{*}{ No. } & \multirow{2}{*}{ Pernyataan } & \multicolumn{4}{|c|}{ Respon } \\
\hline & & SS & $\mathbf{S}$ & TS & STS \\
\hline A. & Indikator : Perasaan Senang & & & & \\
\hline 1. & Saya menyenangi pelajaran matematika (+) & & & & \\
\hline 2. & Saya merasa gelisah ketika mempelajari matematika (-) & & & & \\
\hline 3. & Saya suka belajar memakai aplikasi Geogebra $(+)$ & & & & \\
\hline 4. & suasana kelas jadi menyenangkan $(+)$ & & & & \\
\hline 5. & waktu belajar matematika terlalu lama (-) & & & & \\
\hline B. & Indikator : Ketertarikan Siswa & & & & \\
\hline 6. & Saya memahami materi pelajaran yang guru sampaikan $(+)$ & & & & \\
\hline 7. & Materi yang disampaikan kurang jelas (-) & & & & \\
\hline 8. & materi PGL berbantu aplikasi Geogebra mudah dipahami $(+)$ & & & & \\
\hline 9. & Saya lebih suka belajar dengan cara seperti biasa (-) & & & & \\
\hline 10. & Saya fokus selama proses pembelajaran berlangsung $(+)$ & & & & \\
\hline 11. & $\begin{array}{llll}\text { Pembelajaran menggunakan metode ini sangat } \\
\text { membosankan (-) }\end{array}$ & & & & \\
\hline 12. & saya tidak suka diberi pekerjaan rumah (PR) (-) & & & & \\
\hline C. & Indikator : Keterlibatan Siswa & & & & \\
\hline 13. & $\begin{array}{lccc}\text { Selama pembelajaran matematika } & \text { saya } & \text { berani } \\
\text { mengemukakan pendapat }(+) & & & \\
\end{array}$ & & & & \\
\hline 14. & Saya merasa malu untuk bertanya (-) & & & & \\
\hline D. & Indikator : Rajin dan Semangat Mengerjakan Tugas & & & & \\
\hline 15. & Saya bersemangat mengerjakan soal yang diberikan $(+)$ & & & & \\
\hline 16. & $\begin{array}{l}\text { saya malas membuat catatan matematika yang sudah } \\
\text { diajarkan (-) }\end{array}$ & & & & \\
\hline 17. & $\begin{array}{l}\text { mengerjakan tugas melihat kepada teman, karena saya } \\
\text { belum paham (-) }\end{array}$ & & & & \\
\hline 18. & $\begin{array}{l}\text { Menyelesaikan tugas matematika dan mendapat nilai bagus } \\
\text { adalah sangat penting bagi saya }(+)\end{array}$ & & & & \\
\hline
\end{tabular}




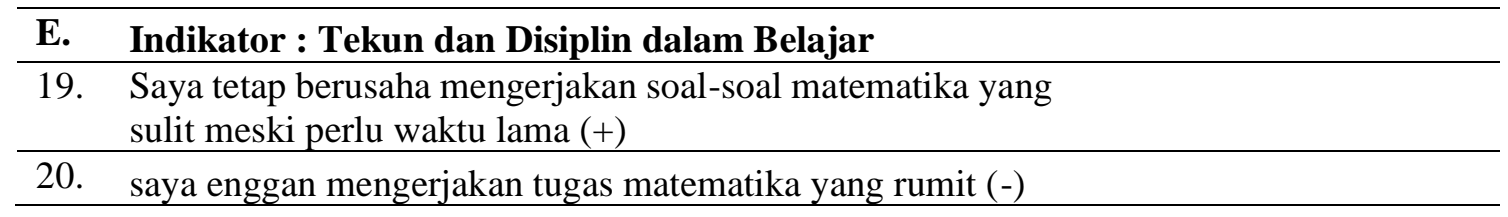

Adapun penskoran dari setiap pernyataan adalah sebagai berikut :

\section{Tabel 2}

Penskoran Setiap Pernyataan

\begin{tabular}{|l|c|c|}
\hline \multirow{2}{*}{\multicolumn{1}{|c|}{ Respon }} & \multicolumn{2}{c|}{ Pernyataan } \\
\cline { 2 - 3 } & Positif & Negatif \\
\hline Sangat Setuju (SS) & 4 & 1 \\
\hline Setuju (S) & 3 & 2 \\
\hline Tidak Setuju (TS) & 2 & 3 \\
\hline Sangat Tidak Setuju (STS) & 1 & 4 \\
\hline
\end{tabular}

Data hasil penelitian yang diperoleh diolah menggunakan Microsoft Excel dengan teknik pengolahan data berdasarkan rumus persentase menurut sudijono yaitu :

$$
P=\frac{f}{n} \times 100 \%
$$

Keterangan:

$\mathrm{P}=$ presentase jawaban

$\mathrm{f}=$ frekuensi jawaban

$\mathrm{n}=$ banyaknya responden

persentase yang telah diperoleh pada masing-masing item pernyataan, kemudian ditafsirkan sesuai dengan kriteria berikut ini :

Tabel 3.

Kriterian Penafsiran Persentase Jawaban Angket

\begin{tabular}{cl} 
Kriteria & \multicolumn{1}{c}{ Penafsiran } \\
\hline $\mathrm{P}=0 \%$ & Tak seorang pun \\
$0 \%<\mathrm{P}<25 \%$ & Sebagian hasil \\
$25 \% \leq \mathrm{P}<50 \%$ & Hampir Setengahnya \\
$\mathrm{P}=50 \%$ & Setengahnya \\
$50 \%<\mathrm{P}<75 \%$ & Sebagian besar \\
$75 \% \leq \mathrm{P} \leq 100 \%$ & Hampir Seluruhnya \\
$\mathrm{P}=100 \%$ & Seluruhnya \\
\hline
\end{tabular}

\section{HASIL}

Hasil dari penelitian ini ialah pengumpulan data skala minat belajar dari responden 32 siswa melalui instrumen non test yaitu angket yang memuat 5 indikator skala sikap minat belajar siswa setelah dilakukan proses pembelajaran pada materi persamaan garis lurus berbantukan aplikasi geogebra .

Setelah dilakukan penelitian, kemudian peneliti melakukan analisis terhadap data yang diperoleh, 
Analisis Minat Belajar Matematika Siswa SMP Kelas VIII Pada Materi Persamaan Garis Lurus Berbantu Aplikasi

maka diperoleh hasil persentase yang dapat dilihat dalam tabel berikut:

Tabel 4

Persentase Skala Sikap Minat Belajar Siswa

\begin{tabular}{|c|c|c|c|c|c|c|}
\hline \multirow{2}{*}{ No. } & \multirow{2}{*}{ Indikator } & \multirow{2}{*}{$\begin{array}{c}\text { Banyak } \\
\text { Pernyataan }\end{array}$} & \multicolumn{3}{|c|}{ Total } & \multirow{2}{*}{ Keterangan } \\
\hline & & & Skor & Mean & Persentase & \\
\hline 1. & Perasaan Senang & 5 & 458 & 91,6 & 71,56 & Sebagian besar \\
\hline 2. & Ketertarikan Siswa & 7 & 631 & 90,1 & 70,42 & Sebagian besar \\
\hline 3. & Keterlibatan Siswa & 2 & 181 & 90,5 & 70,70 & Sebagian besar \\
\hline 4. & $\begin{array}{l}\text { Rajin dan } \\
\text { Semangat } \\
\text { Mengerjakan } \\
\text { Tugas }\end{array}$ & 4 & 363 & 90,8 & 70,90 & Sebagian besar \\
\hline 5. & $\begin{array}{l}\text { Tekun dan Disiplin } \\
\text { dalam Belajar }\end{array}$ & 2 & 178 & 89 & 69,53 & Sebagian besar \\
\hline & Total & 20 & 1811 & 90,4 & 70,74 & Sebagian besar \\
\hline
\end{tabular}

Dari tabel 4 dapat dilihat bahwa rata-rata perolehan persentase tiap indikator adalah 70,74\% dimana sesuai dengan kriteria penafsiran sudah sebagian besar dari siswa telah memiliki minat belajar terhadap kegiatan pembelajaran matematika berbantu aplikasi Geogebra.

Berikut deskriptif statistik visual data minat belajar siswa:

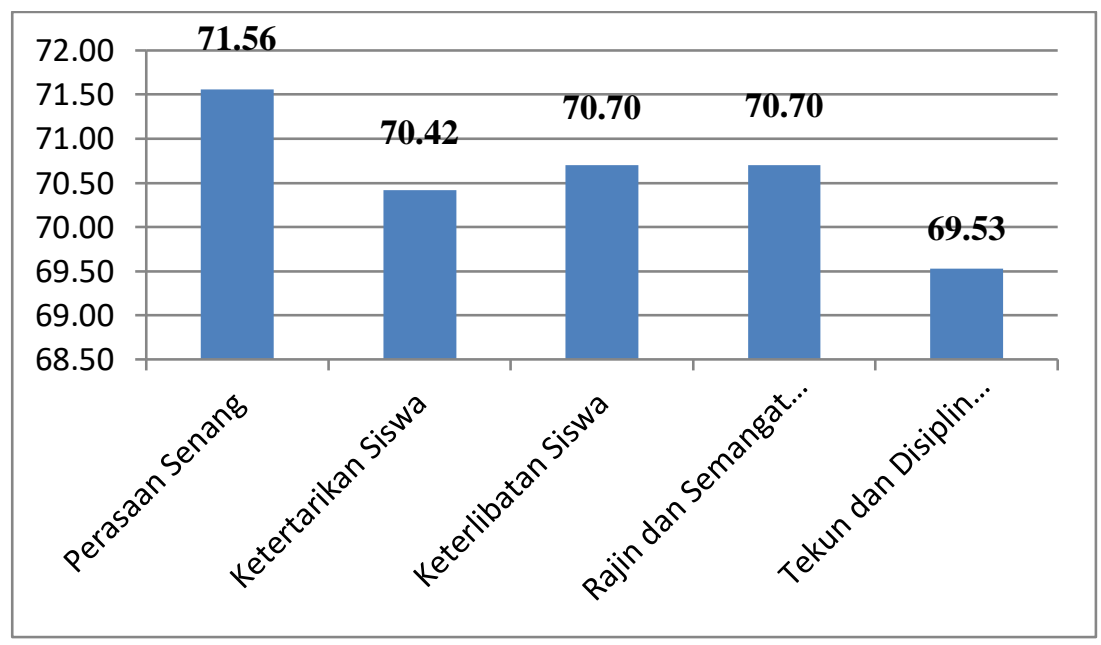

Gambar 1. Diagram Persentase Indikator pada Minat Belajar Siswa

Dilihat dari gambar 1 diagram persentase indikator pada minat belajar siswa untuk indikator perasaan senang diperoleh persentase yang paling unggul yaitu sebesar 71,56\% ,kemudian terlihat bahwa indikator ketertarikan siswa memperoleh persentase $70,42 \%$. Selain itu pada indikator keterlibatas siswa juga pada indikator rajin dan semangat mengerjakan tugas memperoleh hasil yang sama yaitu pada persentase $70,70 \%$. Terakhir pada indikator tekun dan disiplin dalam belajar menjadi indikator yang memperoleh hasil paling rendah dari semua indikator yaitu hanya 69,53\%. Dari kelima indikator sudah hampir sebagian besar siswa telah mempunyai minat belajar pada pembelajaran matematika dengan berbantu aplikasi Geogebra. 
Dari data diatas terlihat bahwa minat belajar pada siswa SMP dalam pembelajaran berbantukan aplikasi Geogebra pada materi persamaan garis lurus mendapat respon yang positif. Hal ini disebabkan karena kegiatan pembeajaran lebih menarik dan tidak monoton sehingga dapat meningkatkan minat belajar siswa pada khususnya pada pembelajaran matematika. Dengan adanya minat belajar pada siswa akan memudahkan terlaksananya tujuan pembelajaran dan tentu akan berpengaruh positif terhadap keberhasilan pembelajaran matematika pada siswa (Flora Siagian, 2015).

\section{KESIMPULAN}

Dari hasil analisis terhadap data yang telah diperoleh dan pembahasan yang disajikan diatas dapat diambil kesimpulan bahwa pembelajaran persamaan garis lurus pada siswa SMP kelas VIII SMP Pasundan 9 Bandung yang pembelajarannya berbantu aplikasi Geogebra mendapat respon positif dan dapat meningkatkan minat belajar matematis siswa. Hal tersebut terlihst dari diperolehnya rata-rata persentase tiap indikator yaitu $70,74 \%$ yang berarti sudah sebagian besar siswa telah mempunyai minat belajar pada pembelajaran matematika yang berbantu aplikasi Geogebra.

Untuk penelitian berikutnya, diharapkan peneliti lain dapat mengembangkan hasil dari penelitian ini dengan lebih baik dengan pemanfaatan aplikasi Geogebra untuk meningkatkan minat dan hasil belajar siswa .

\section{DAFTAR PUSTAKA}

Farihah, U. (2015). Pengaruh Program Interaktif Geogebra Terhadap. 1(1), 11-23.

Flora Siagian, R. E. (2015). Pengaruh Minat dan Kebiasaan Belajar Siswa terhadap Prestasi Belajar Matematika. Formatif: Jurnal Ilmiah Pendidikan MIPA, 2(2), 122-131. https://doi.org/10.30998/formatif.v2i2.93

Hendriana, H., Rohaeti, E. S., \& Sumarmo, U. (2017). Hard Skills snd Soft Skills Matematika Siswa. PT. Refika Aditama.

Lestari, I. (2015). Pengaruh Waktu Belajar dan Minat Belajar terhadap Hasil Belajar Matematika. Formatif: Jurnal Ilmiah Pendidikan MIPA, 3(2), 115-125. https://doi.org/10.30998/formatif.v3i2.118

Nur, I. M. (2016). Pemanfaatan Program Geogebra dalam Pembelajaran Matematika. Jurnal Matematika Dan Pendidikan Matematika, 5(1), 10-19. https://doi.org/10.1038/oncsis.2016.1

Pratiwi, B. L., Kuswardi, Y., \& Fitriana, L. (2018). Upaya Peningkatan Motivasi Belajar Siswa melalui Model Pembelajaran Problem Based Learning dengan Strategi ARCS (Attention, Relevance, Confidence, Satisfaction) pada Siswa Kelas XI IPA 2 SMA Negeri 1 Pertahanan Tahun Pelajaran 2017/2018. Jurnal Pendidikan Matematika Dan Matematika (JPMM), 2(2), 161-169.

Putra, H. D., Setiawan, H., Nurdianti, D., Retta, I., Desi, A., \& A. (2018). Kemampuan Pemahaman matematis siswa SMP di bandung barat. 11, 19-30.

Sholihah, D. A., \& Mahmudi, A. (2015). Keefektifam Experiential Learning Pembelajaran Matematika 
Analisis Minat Belajar Matematika Siswa SMP Kelas VIII Pada Materi Persamaan Garis Lurus Berbantu Aplikasi

MTs Materi Bangun Ruang Sisi Datar. Jurnal Riset Pendidikan Matematika, 2(2), 175-185. https://doi.org/10.21831/jrpm.v2i2.7332

Sihwidi, J. (2016). Penggunaan Geogebra untuk Meningkatkan Aktivitas dan Penguasaan Kompetensi Transformasi Geometri di SMKN 1 Tulang Bawang Tengah. Indonesian Digital Journal of Mathematics and Education, 3(4), 208-220.

Widyaningrum, Y. T., \& Murwanintyas, C. E. (2013). Pengaruh Media Pembelajaran Geogebra terhadap Grafik Fungsi Kuadrat Di Kelas X SMA Negeri 2 Yogyakarta Tahun Pelajaran 2012/2013. (November 2012), 978-979. 